Article

\title{
CFD Study on Aerodynamic Power Output Changes with Inter-Turbine Spacing Variation for a 6 MW Offshore Wind Farm
}

\author{
Nak Joon Choi ${ }^{1}$, Sang Hyun Nam ${ }^{2}$, Jong Hyun Jeong ${ }^{2}$ and Kyung Chun Kim ${ }^{1, *}$ \\ 1 School of Mechanical Engineering, Pusan National University, San 30, Jangjeon-dong, \\ Geumjeong-Gu, Busan 609-735, Korea; E-Mail: njchoi@dnde.co.kr \\ 2 DNDE Inc., Busan 612-020, Korea; E-Mails: shnam@dnde.co.kr (S.H.N.); \\ jhjeong@dnde.co.kr (J.H.J.) \\ * Author to whom correspondence should be addressed; E-Mail: kckim@pusan.ac.kr; \\ Tel.: +82-51-510-2324; Fax: +82-51-515-7866.
}

External Editor: Frede Blaabjerg

Received: 1 July 2014; in revised form: 10 November 2014 / Accepted: 11 November 2014 / Published: 18 November 2014

\begin{abstract}
This study examined the aerodynamic power output change of wind turbines with inter-turbine spacing variation for a $6 \mathrm{MW}$ wind farm composed of three sets of $2 \mathrm{MW}$ wind turbines using computational fluid dynamics (CFD). The wind farm layout design is becoming increasingly important as the use of wind energy is steadily increasing. Among the many wind farm layout design parameters, the inter-turbine spacing is a key factor in the initial investment cost, annual energy production and maintenance cost. The inter-turbine spacing should be determined to maximize the annual energy production and minimize the wake effect, turbulence effect and fatigue load during the service lifetime of wind turbines. Therefore, some compromise between the aerodynamic power output of wind turbines and the inter-turbine spacing is needed. An actuator disc model with the addition of a momentum source was not used, and instead, a full 3-dimensional model with a tower and nacelle was used for CFD analysis because of its great technical significance. The CFD analysis results, such as the aerodynamic power output, axial direction wind speed change, pressure drop across the rotor of wind turbine, and wind speed deficit due to the wake effect with inter-turbine spacing variation, were studied. The results of this study can be applied effectively to wind farm layout design and evaluation.
\end{abstract}


Keywords: aerodynamic power output; CFD (computational fluid dynamics); inter-turbine spacing; layout; offshore wind farm

\section{Introduction}

The increase in $\mathrm{CO}_{2}$ concentration in the atmosphere due to fossil fuel usage has resulted in global warming and climate change, which poses a threat to society. To overcome these problems, a reduction of $\mathrm{CO}_{2}$ emissions is using renewable energy essential [1]. Among the many renewable energy resources, wind energy is the most competitive and its cost of production is reaching the same level as that of coal fired and nuclear power plants. Therefore, the market for wind energy is expected to increase steadily.

Wind turbines are a kind of energy extractor or converter [2]. The kinetic energy of free stream air is converted into mechanical rotational energy by a rotor and finally converted into electrical energy at the generator. The recent technology trend in wind energy has been toward offshore wind farms composed of multi-MW wind turbines. Offshore wind farms have several advantages over onshore or inland wind farms, such as better wind conditions and more annual energy production but the initial investment cost is much higher than that of onshore wind farms due to the high foundation and erection costs [3].

The layout design of offshore wind farms is a key factor that affects the initial investment cost, annual energy production, operation and maintenance cost during the service life time of wind turbines [4]. If the inter-turbine spacing is too narrow, the downstream wind turbine is affected seriously by the wake from the upstream wind turbine and the aerodynamic power output is reduced by the wind speed deficit. The service life time of the downstream wind turbine is reduced by the fatigue load but the cable laying cost is also reduced. Contradictory results are anticipated in the case of high inter-turbine spacing. Therefore, some compromise between the inter-turbine spacing and aerodynamic power output is needed [5].

To study the aerodynamic power output of an offshore wind farm with $2 \mathrm{MW}$ class wind turbines according to the inter-turbine spacing, an experimental method is unrealistic because of the high cost required and length of time involved. The computational fluid dynamics (CFD) approach can be successfully applied with minimum cost and time compared to the experimental method [6]. Before computer resources reached an adequate level, it was only possible to analyze a wind farm with an actuator disk, momentum source, and rather coarse elements, as used in previous wind farm CFD study results with various limitations [7]. Due to the rapid development of computer resources, it is now possible to analyze an entire wind farm and evaluate sites with a full three-dimensional (3-D) wind turbine model, as used in this wind farm CFD analysis. The tilted rotor, nacelle and tower must be considered to simulate an actual wind turbine. To the best of knowledge, no research has been reported in the literature that describes a CFD wind farm analysis using a full wind turbine model.

In this study, computational fluid dynamics (CFD) analysis of the aerodynamic power output of $6 \mathrm{MW}$ offshore wind farms composed of three sets of $2 \mathrm{MW}$ wind turbines according to the interturbine spacing was performed. An actuator disc model with the addition of a momentum source was not used, and instead, a full 3-D model was used for the precise aerodynamic power output calculations 
by CFD analysis. CFD analysis can be used to analyze large-scale problems, and the application of CFD to the layout design of offshore wind farms is expected to proliferate rapidly as the offshore wind farm market grows.

\section{Inter-Turbine Spacing and Layout}

Figure 1 shows various layout designs of wind farms depending on the site conditions, access convenience and maintenance conditions. The layout design of wind farms will become increasingly important as offshore wind farm with larger capacity are developed [8,9]. In the wake region, there is a wind speed deficit, which affects the annual energy production. Far downstream, a merged wake from the multiple wakes occurs, which makes it impossible to calculate the annual energy production analytically. The level of the wake effect on a downstream wind turbine is connected directly to the inter-turbine spacing. If the inter-turbine spacing is too narrow, the wake effect, such as the wind speed deficit, becomes dominant. If the inter-turbine spacing is wide, the wake effect is weak and the incoming wind speed to the rotor of the downstream wind turbine recovers. This results in a higher aerodynamic power output.

Although there are many possible layouts for a wind farm as shown in Figure 1, the in-line configuration turns out to be a canonical layout for an offshore wind farm. The power deficit of the downstream wind turbines is mainly caused by wake flows from the upstream wind turbines, therefore, only one flow direction which is parallel to the wind turbines is considered.

Figure 1. Various wind farm layout designs.

$\oplus \oplus \oplus \oplus \oplus \oplus \oplus \oplus \oplus \oplus \oplus \oplus \oplus \oplus \oplus \oplus \oplus \oplus \oplus \oplus \oplus \oplus \oplus \oplus \oplus \oplus \oplus$

Linear (Plan view)

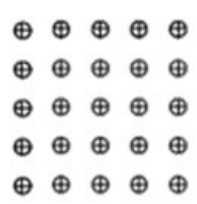

$\oplus \oplus \oplus \oplus \oplus$

$\oplus \oplus \oplus \oplus \oplus$

$\oplus \oplus \oplus \oplus \oplus$

$\oplus \oplus \oplus \oplus \oplus$

$\oplus \oplus \oplus \oplus \oplus$

Basic grid (Plan view) Offset grid (Plan view)

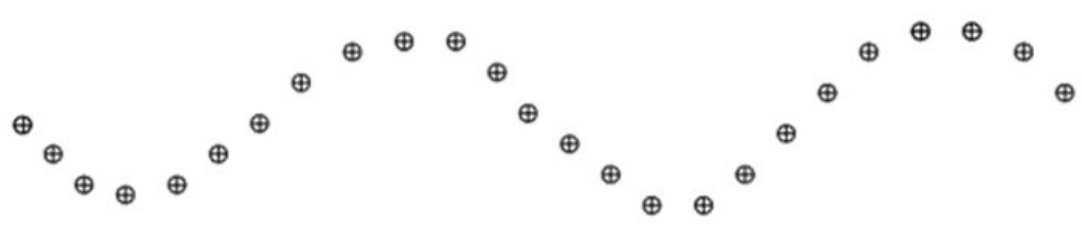

Arced (Plan view)

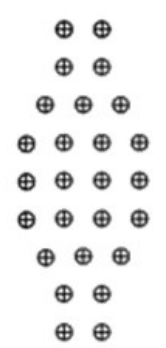

$$
\begin{aligned}
& \oplus \oplus \oplus \\
& \oplus \oplus \oplus \oplus \\
& \stackrel{\oplus}{\oplus \oplus \oplus} \oplus \oplus
\end{aligned}
$$

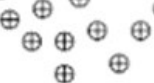

Random (Plan view) 


\section{Wind Turbine and Wind Farm Configuration}

For this study, a $2 \mathrm{MW}$ wind turbine was designed and modeled with a tilted rotor, nacelle and tower. The electrical power output of the horizontal axis wind turbine can be expressed as:

$$
P_{\text {gen }}=\frac{1}{2} \rho\left(\pi \frac{D^{2}}{4}\right) U_{\infty}^{3} \eta C_{\mathrm{p}}
$$

where:

$P_{\text {gen }}$ - electrical power output of wind turbine, $\mathrm{W}$;

$\rho$-normal value of air density, $\mathrm{kg} / \mathrm{m}^{3}$;

$D$-rotor diameter, $\mathrm{m}$;

$U_{\infty}$-wind speed, $\mathrm{m} / \mathrm{s}$;

$\eta$-overall efficiency;

$C_{p}$-power coefficient [10].

The power coefficient can be written as:

$$
C_{\mathrm{p}}=\frac{P_{\text {aero }}}{\frac{1}{2} \rho\left(\pi \frac{D^{2}}{4}\right) \mathrm{U}_{\infty}^{3}}
$$

where $P_{\text {aero }}$-aerodynamic power output of wind turbine, W [11].

The blade is designed using blade element momentum theory, Equations (1) and (2). Wind turbine blade design software called XD-BLADE, developed by Choi et al. [12], was used for the detailed blade design. The main specifications of a $2 \mathrm{MW}$ wind turbine are $84.2 \mathrm{~m}$ of rotor diameter, $11 \mathrm{~m} / \mathrm{s}$ of rated wind speed, $5^{\circ}$ of tilt angle, $18.7 \mathrm{rpm}$ of rotational speed, and 7.5 of tip speed ratio. The hub height is $85.2 \mathrm{~m}$.

Figure 2 shows the layout of a $6 \mathrm{MW}$ offshore wind farm for CFD analysis including inter-turbine spacing parameter and wind turbine identification. L1 means the distance from the inlet of the domain to the wind turbine WT1, and L2 means the inter-turbine spacing varying from 3D to 7D. L3 means the distance from wind turbine WT3 to the outlet of the domain.

Figure 2. 6 MW offshore wind farm layout and wind turbine identification.

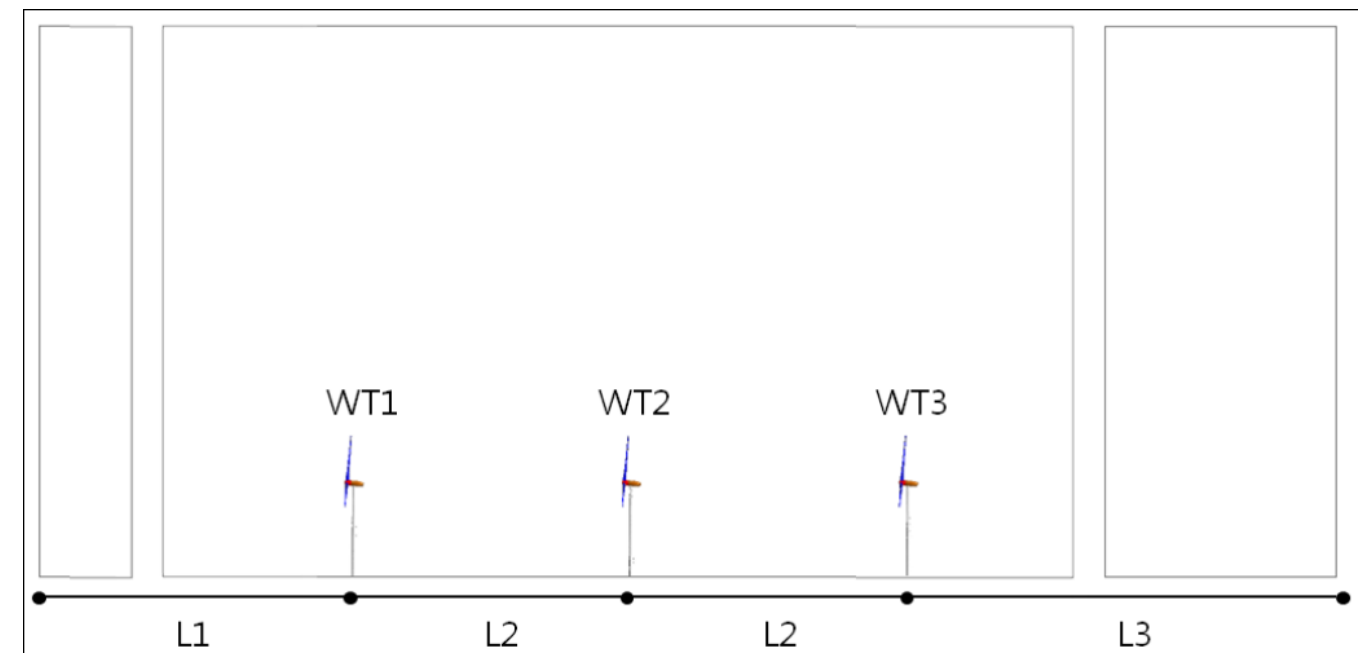




\section{CFD Analysis}

CFD analysis was carried out according to the inter-turbine spacing variation. Table 1 lists the analysis cases according to the inter-turbine spacing based on the wind turbine rotor diameter D. The distance from the inlet to the upstream wind turbine, L1 was 7D. L2 was changed from 3D to 7D. The height and width of the wind farm flow field were 6D, 10D, respectively, and the distance from the downstream wind turbine to the outlet was kept at 17D.

Table 1. Analysis cases according to inter-turbine spacing.

\begin{tabular}{ccccc}
\hline No. of analysis case & L1 & L2 & L3 & Remark \\
\hline Case 1 & $7 \mathrm{D}$ & 3D & $17 \mathrm{D}$ & \\
Case 2 & $7 \mathrm{D}$ & 4D & $17 \mathrm{D}$ & \\
Case 3 & $7 \mathrm{D}$ & 5D & $17 \mathrm{D}$ & $\mathrm{D}=84.2 \mathrm{~m}$ \\
Case 4 & $7 \mathrm{D}$ & $6 \mathrm{D}$ & $17 \mathrm{D}$ & \\
Case 5 & $7 \mathrm{D}$ & 7D & 17D & \\
\hline
\end{tabular}

Table 2 presents the mesh system information for a $6 \mathrm{MW}$ offshore wind farm for analysis case 3 . The real scale of computational domain for case 3 is $842 \mathrm{~m}$ (width) $\times 505.2 \mathrm{~m}$ (height) $\times 2441.8 \mathrm{~m}$ (length) This CFD analysis is a large-scale computational problem because the number of elements reaches approximately 14.3 million. Grid tests were performed only for case 3 and there was no variation in power coefficients when the number of grid elements was over 14 million. The frozen-rotor interface scheme is used for the analysis. It supports steady-state prediction in the local frame of reference on each side of the interface. The mesh system is divided into two parts; the rotational and stationary region. The relative position of the rotational region to the stationary region is frozen in time. Figure 3 shows the rotational region mesh system including the rotor with blades. Hexahedral mesh is used for the convergence and precise aerodynamic power output calculations. The mesh density of the rotational region is much higher than that of the stationary region for a more precise power output calculation. $\mathrm{Y}^{+}$value of the blade is about 4, except for the root region of the blade as shown in Figure 3. The rotational direction of the rotor is clockwise and the rotational phase of each wind turbine is synchronized.

Figure $4 \mathrm{a}$ shows the total mesh system, including the rotational and stationary regions for the representative example of case 3. The tetrahedral and prism mesh were used for the stationary region mesh system. Figure $4 \mathrm{~b}$ shows the regions of the boundary conditions for the inlet, outlet, top, bottom and two sides. The tilting angle of the $2 \mathrm{MW}$ class wind turbine was set to $5^{\circ}$. For tilted rotor, the application of a periodic boundary condition is impossible. Table 3 lists the detailed boundary conditions.

The atmospheric boundary layer velocity profile at sea level was applied to the inlet region in order to taking account of the wind shear effect. The inlet turbulence intensity was $18 \%$. The wind shear obeying the power law can be expressed as:

$$
U=U_{r e f}\left(\frac{Z}{Z_{r e f}}\right)^{\alpha}
$$

where:

$U$ —wind speed according to the height, $\mathrm{m} / \mathrm{s}$;

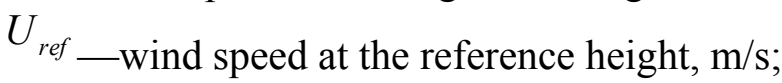


$Z$ - height, m;

$Z_{\text {ref }}$-reference height, m;

$\alpha$-power law exponent [13].

In this study, the reference height was the hub height and the power law exponent $\alpha$ was 0.1 . A relative (gage) pressure of $0 \mathrm{~Pa}$ based on the atmospheric pressure was applied to the outlet. Free-slip condition was applied to the top surface. This means that there is no wind speed gradient vertically and no flow across the top surface. The free-slip condition can be expressed as:

$$
\frac{\partial U}{\partial Z}=0
$$

The bottom is considered as sea surface and the no-slip condition is applied. An air density of $1.225 \mathrm{~kg} / \mathrm{m}^{3}$ was applied based on IEC 61400-1 [14].

Steady state analysis was carried out. The rotational region had a rated rotational speed of $18.7 \mathrm{rpm}$, so the interface was considered to change the coordinate system between the rotational region and the stationary region. A commercial multi-purpose CFD solver ANSYS CFX (ver. 12.1) was used for the wind farm simulation. RANS-based shear stress transport with a transition model (SST model) was selected for turbulence model [15]. The SST model is based on the $\kappa-\omega$ model near the wall. So, the SST model turns out powerful to predict turbulent frequency in the boundary layer. The CFD analysis was carried out with a parallel computer using Linux cluster with 48 processing cores (Intel Xeon $\mathrm{X} 5650,2.66 \mathrm{GHz}$ ). The solution was iterated until the residues for each equation was less than $10^{-3}$. In general, the residues for the momentum equations was below $10^{-5}$, which for the turbulent kinetic energy was well below $10^{-4}$ and that for the turbulent energy dissipation rate was well below $10^{-3}$.

Table 2. Mesh information for analysis domain of $6 \mathrm{MW}$ wind farm (case 3).

\begin{tabular}{ccc}
\hline Item & No. of nodes & No. of elements \\
\hline Rotational region & $12,089,106$ & $11,618,532$ \\
Stationary region & 563,712 & $2,692,118$ \\
\hline
\end{tabular}

Figure 3. Rotational region and blade surface mesh system.
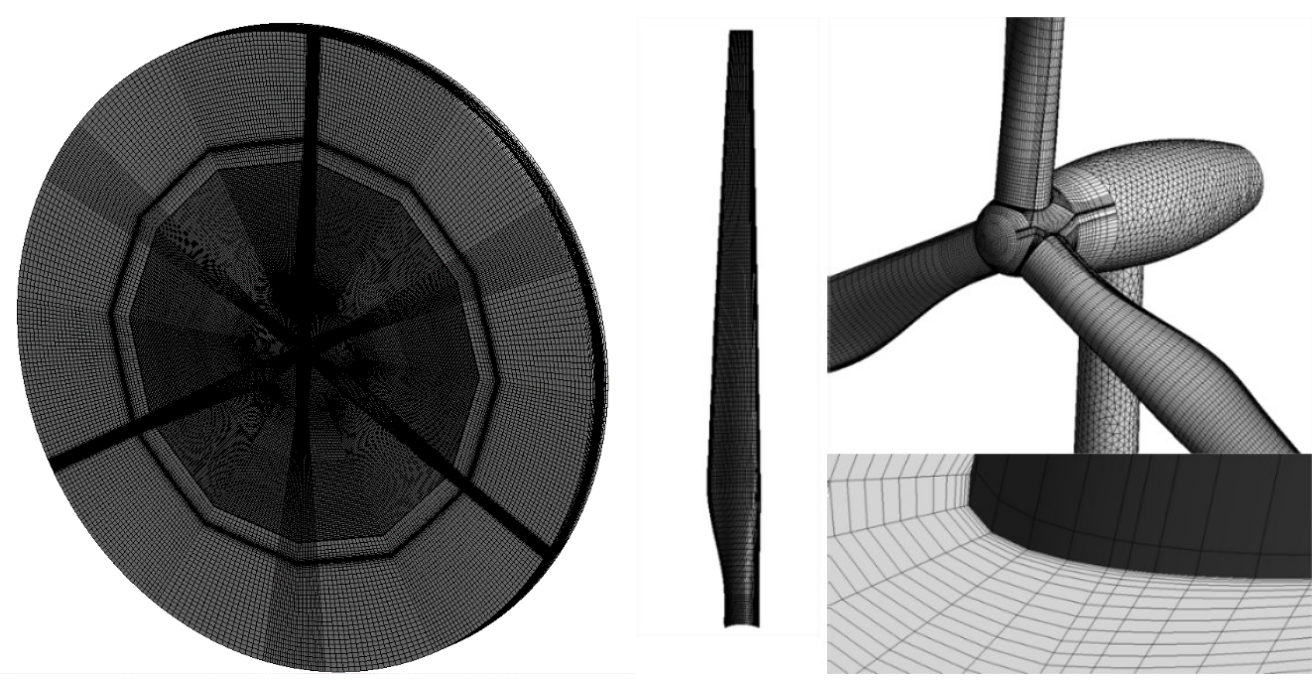
Figure 4. (a) Stationary region mesh system; and (b) Boundary conditions.

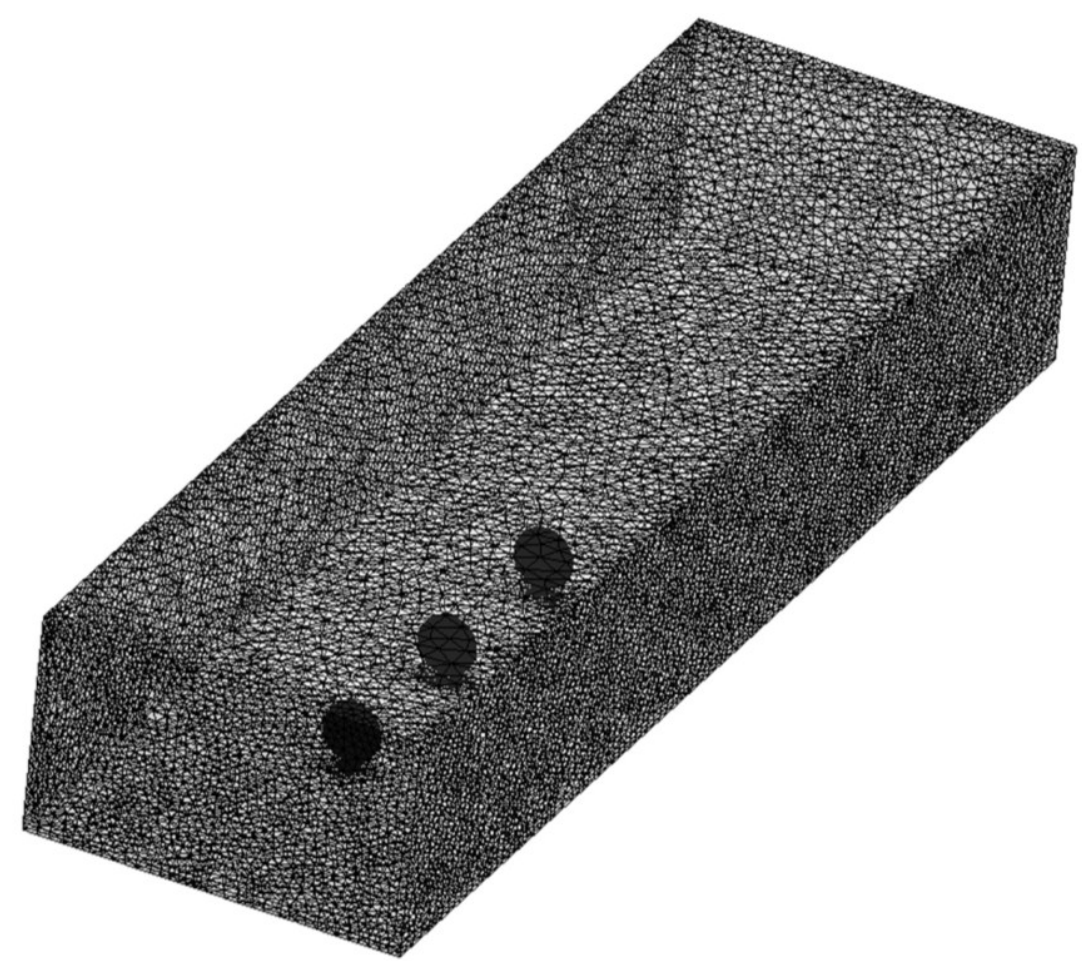

(a)

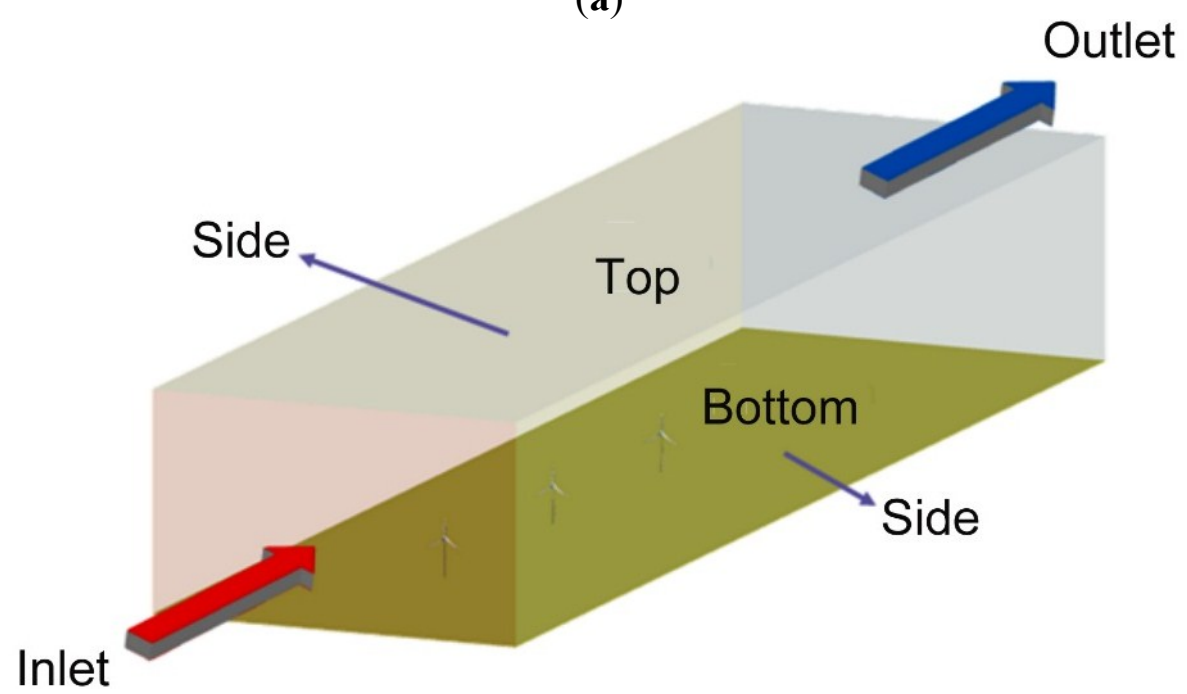

(b)

Table 3. Boundary conditions.

\begin{tabular}{cc}
\hline Item & Description \\
\hline Inlet & $11 \mathrm{~m} / \mathrm{s}$ at the reference height with wind shear \\
Outlet & Atmospheric pressure \\
Side & Symmetry \\
Top & Free-slip condition \\
Bottom & No-slip condition \\
\hline
\end{tabular}




\section{Results and Discussion}

Table 4 lists the CFD analysis results for a $6 \mathrm{MW}$ offshore wind farm. The aerodynamic power output of wind turbine WT1 was increased slightly with increasing inter-turbine spacing L2. The power increase in case 5 was $3.7 \%$ compared to that of case 1 . The downstream wind turbines, WT2 and WT3, were considered to be the flow resistance [16]. If the inter-turbine spacing L2 increases, the flow resistance is located away from the wind turbine WT1 and the back pressure is reduced. For this reason, the flow to wind turbine WT1 and downstream direction is less resistive and the aerodynamic power output of wind turbine WT1 increases slightly in turn.

The aerodynamic power output of wind turbines WT2 and WT3 was surprisingly lower than that of wind turbine WT1. In case of L2 = 3D, 2 MW turbines WT2 and WT3 produce only $309 \mathrm{~kW}$ and $74 \mathrm{~kW}$, respectively. However, the powers recovered to $56 \%$ and $44 \%$ of the power of WT1 when L2 increases from 3D to 7D. In theory, complete recovery of the power output of a downstream wind turbine requires an infinite separation distance between wind turbines. If enough separation distance is secured for the enhancement of the power output of a downstream wind turbine, more transmission cable is required and the cable laying cost rises. The aerodynamic power output of wind turbine WT2 is affected by the wake from wind turbine WT1 while the aerodynamic power output of wind turbine WT3 is affected by the wake from wind turbines WT1 and WT2. Therefore, the incoming wind speed deficit is higher for wind turbine WT3 than for wind turbine WT2. This is why the aerodynamic power output of wind turbine WT3 is much smaller than that of wind turbine WT2. More detail discussions about power deficits with respect to inter-turbine distance will be addressed with velocity and pressure profiles later.

As the inter-turbine distance L2 increased, the wake effect decreased; then, the axial direction wind speed recovered and power output finally increased. The increasing ratio of aerodynamic power output was higher for the inter-turbine spacing from $3 \mathrm{D}$ to $5 \mathrm{D}$ than that for the inter-turbine spacing from $5 \mathrm{D}$ to $7 \mathrm{D}$. As the inter-turbine spacing was increased from $3 \mathrm{D}$ to $5 \mathrm{D}$, the wake effect weakened rapidly and the wind speed recovered higher. Consequently, the aerodynamic power output of wind turbines WT2 and WT3 increased rapidly. For the range L2 from 5D to 7D, the power output change of the downstream wind turbine was not significant. This behavior suggests that a relatively small increase in the power output of the downstream wind turbine can be expected even though the inter-turbine distance L2 increased beyond 7D.

Figure 5 shows the aerodynamic power output of wind turbines WT2 and WT3 according to the inter-turbine distance variation. The curve shows a nonlinear relationship with respect to the inter-turbine distance between wind turbines. The slope of power increase is different between the regions of $\mathrm{L} 2$ is $3 \mathrm{D}$ to $5 \mathrm{D}$ and $5 \mathrm{D}$ to $7 \mathrm{D}$. The slope difference is very important because it affects significantly to the annual energy production and income of electricity sales for larger wind farms. The slope changes significantly at the inter-turbine distance of 5D. This point can be chosen as a criterion to divide the strong wake region from the weak wake region. 
Table 4. CFD analysis results for $6 \mathrm{MW}$ offshore wind farm.

\begin{tabular}{|c|c|c|c|c|}
\hline No. of analysis case & Wind turbine ID. & $\begin{array}{c}\text { Aerodynamic } \\
\text { power output }(\mathrm{kW})\end{array}$ & $\begin{array}{l}\text { Power ratio } \\
\text { (WT2/WT1) }\end{array}$ & $\begin{array}{l}\text { Power ratio } \\
\text { (WT3/WT1) }\end{array}$ \\
\hline \multirow{3}{*}{ Case 1} & WT1 & 2030 & \multirow{3}{*}{$15 \%$} & \multirow{3}{*}{$3.6 \%$} \\
\hline & WT2 & 309 & & \\
\hline & WT3 & 74 & & \\
\hline \multirow{3}{*}{ Case 2} & WT1 & 2052 & \multirow{3}{*}{$30 \%$} & \multirow{3}{*}{$18 \%$} \\
\hline & WT2 & 611 & & \\
\hline & WT3 & 364 & & \\
\hline \multirow{3}{*}{ Case 3} & WT1 & 2065 & \multirow{3}{*}{$41 \%$} & \multirow{3}{*}{$29 \%$} \\
\hline & WT2 & 838 & & \\
\hline & WT3 & 607 & & \\
\hline \multirow{3}{*}{ Case 4} & WT1 & 2068 & \multirow{3}{*}{$49 \%$} & \multirow{3}{*}{$35 \%$} \\
\hline & WT2 & 1007 & & \\
\hline & WT3 & 718 & & \\
\hline \multirow{3}{*}{ Case 5} & WT1 & 2106 & \multirow{3}{*}{$56 \%$} & \multirow{3}{*}{$44 \%$} \\
\hline & WT2 & 1185 & & \\
\hline & WT3 & 917 & & \\
\hline
\end{tabular}

Figure 5. Aerodynamic power output of wind turbine WT2 and WT3 according to inter-turbine distance variation.

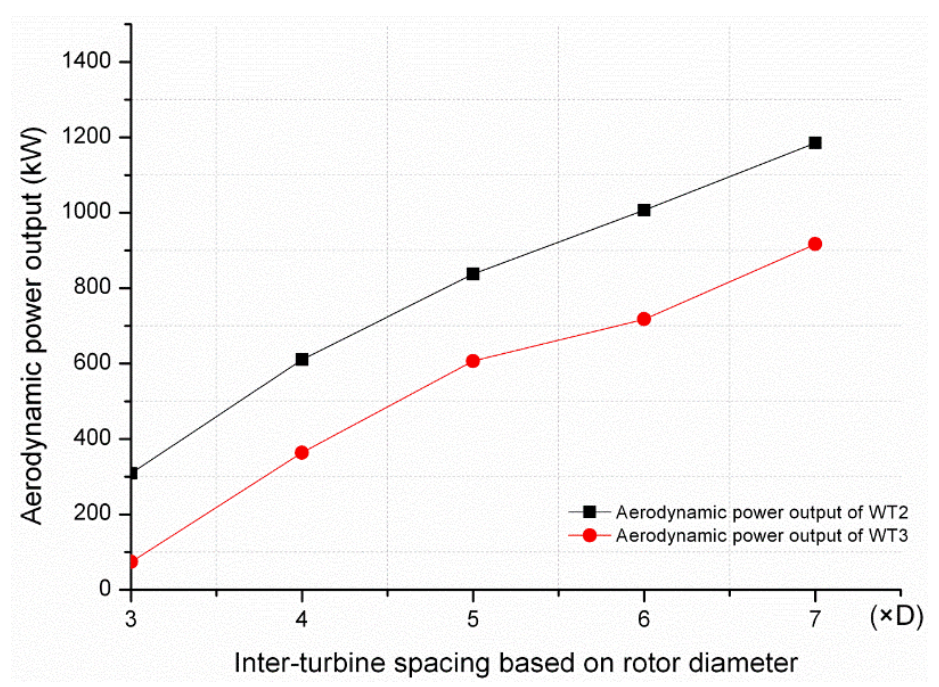

Figure $6 \mathrm{a}-\mathrm{c}$ show the contours of the axial direction wind speed in the horizontal plane at the reference height for the analysis case 1, 3 and 5, respectively. These figures are meaningful to understand overall wake flow regions with respect to the inter-turbine distance. As the inter-turbine spacing increased, the interaction between wind turbines became weak and the aerodynamic power out of the wind turbines increased [17]. In case 1, both WT2 and WT3 are located in strong wake region. In case 2, WT2 is located in weak wake region while WT3 is located in strong wake region. In case 3, both WT2 and WT3 are located in weak wake region. Note that the span-wise width of the wake region becomes narrower when the inter-turbine distance increases. Owing to the axial direction wind speed deficit by axial flow induction factor, the tangential wind speed increased with decreasing axial direction wind speed. This explains why the stream-tube expands. 
Figure 7 shows the profile of axial direction wind speed along the centerline at the reference height location for analysis case $3(\mathrm{~L} 2=5 \mathrm{D})$. In theory, the aerodynamic power output was proportional to the cube of the wind speed. This means that the aerodynamic power output changes dramatically with slight changes in wind speed. The axial direction wind speed decreased across the rotor of wind turbine WT1, recovered slightly and then decreased across the rotor of wind turbine WT2. The same phenomenon was observed for the wind turbine WT3. The axial wind speed past the rotor of wind turbine WT3 recovered gradually and close to the incoming reference wind speed at far downstream.

Figure 6. Axial direction wind speed contours in horizontal plane at the reference height. (a) $\mathrm{L} 2=3 \mathrm{D} ;$ (b) $\mathrm{L} 2=5 \mathrm{D} ;$ (c) $\mathrm{L} 2=7 \mathrm{D}$.

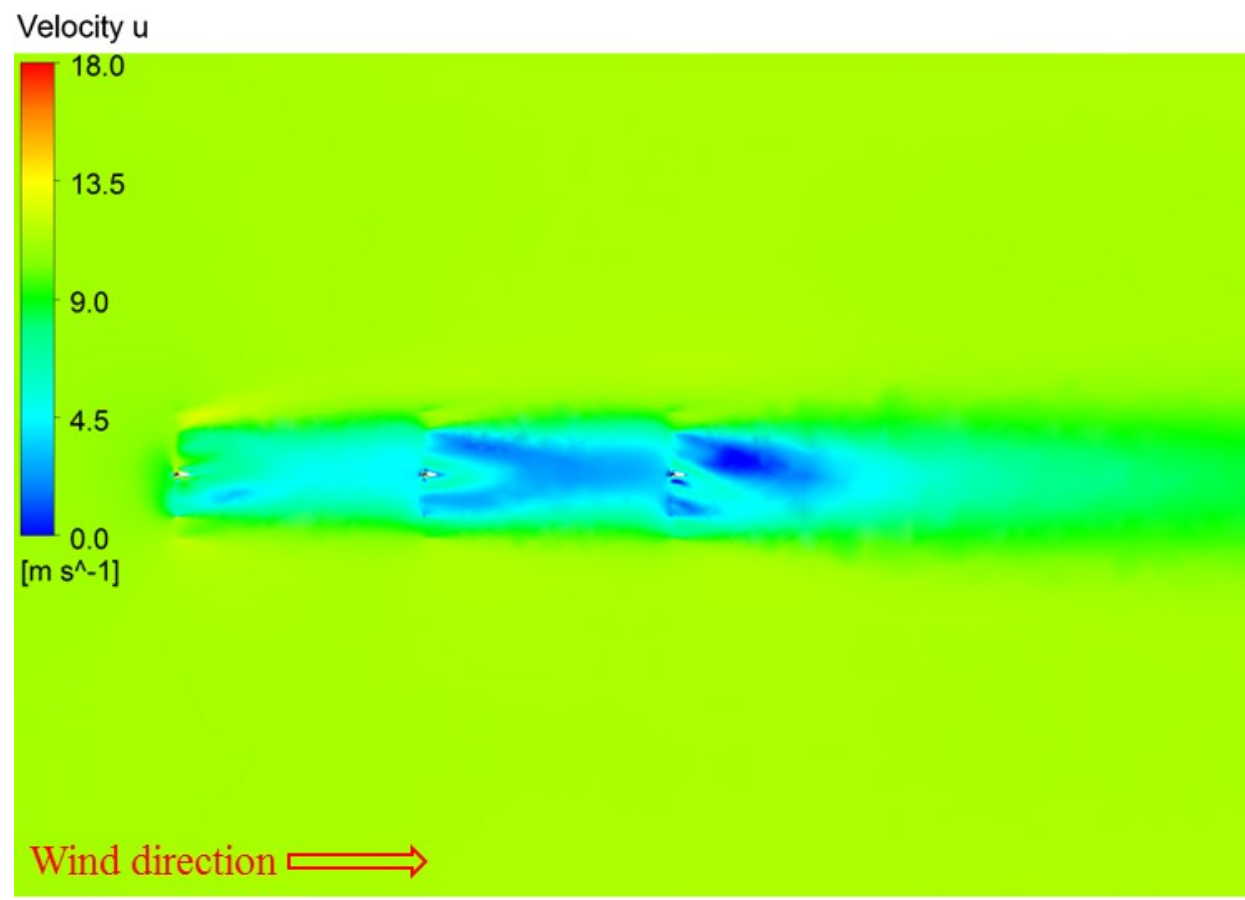

(a)

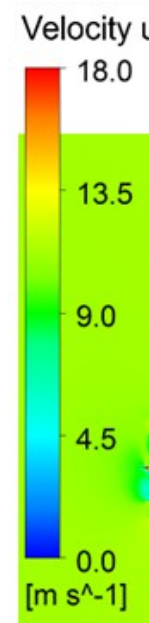

\section{Wind direction $\rightleftarrows$}

(b) 
Figure 6. Cont.

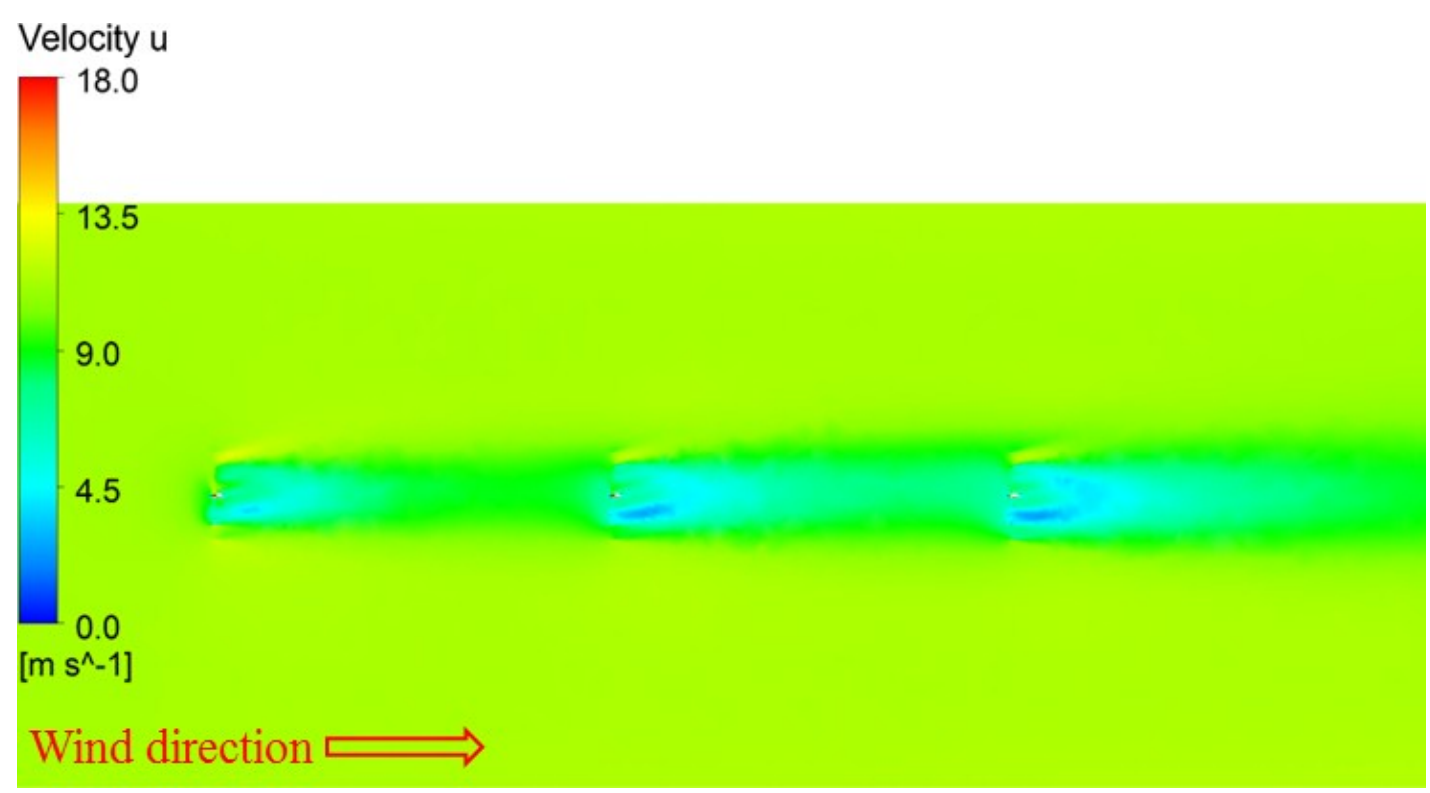

(c)

Figure 7. Axial direction wind speed profile along the center line at the reference height in case $3(\mathrm{~L} 2=5 \mathrm{D})$.

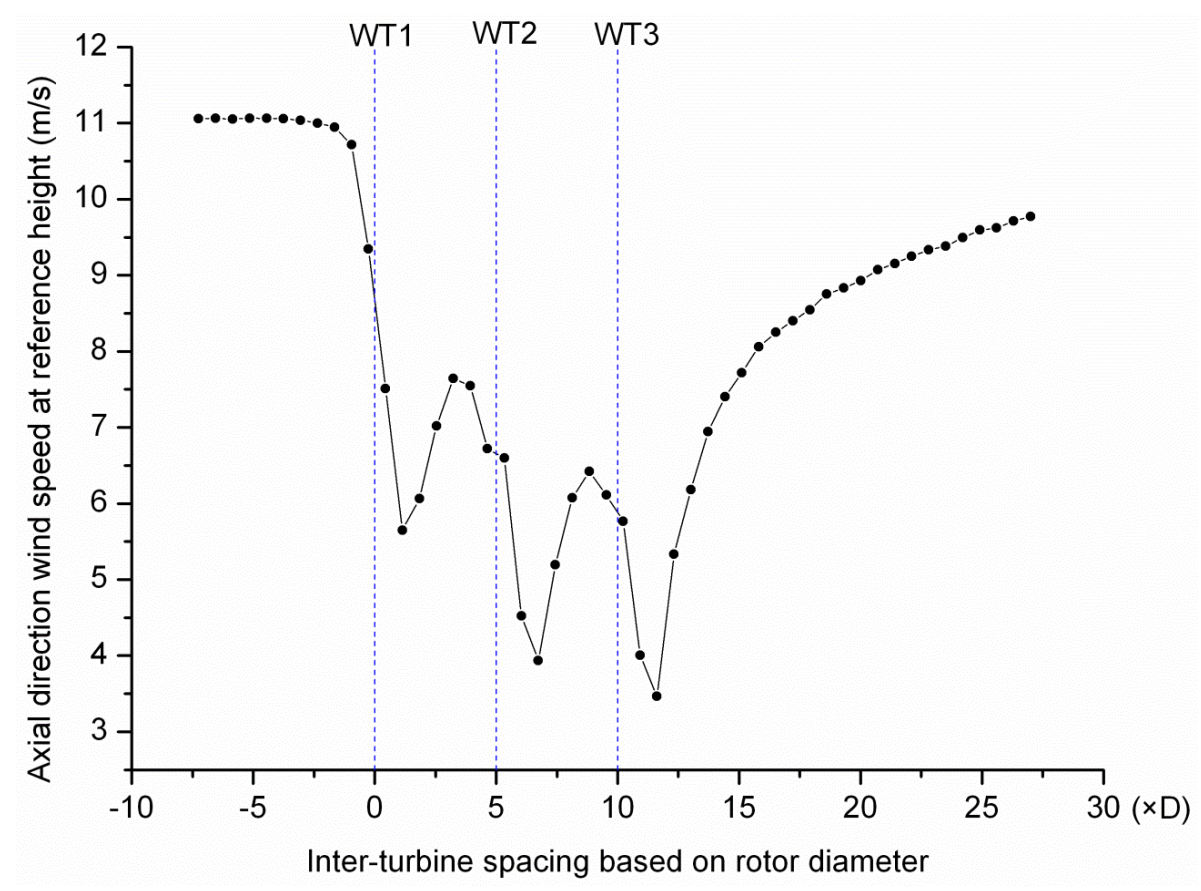

The decrease in the axial direction wind speed was caused by energy extraction by the wind turbine rotor. If the wind undergoes a greater energy extraction process, the aerodynamic power output of the downstream wind turbine is much smaller. An increase in the wind inter-turbine spacing contributes to the axial direction wind speed recovery and higher aerodynamic power output. The maximum axial direction wind speeds in front of WT1, WT2, and WT3 are $11.0 \mathrm{~m} / \mathrm{s}, 7.7 \mathrm{~m} / \mathrm{s}$, and $6.5 \mathrm{~m} / \mathrm{s}$, respectively. The ratio of the cube of maximum wind speed for WT2/WT1 is 0.343 while the ratio for WT3/WT1 is 0.206 . The corresponding power ratio is $41 \%$ and $29 \%$, respectively. The decreasing 
tendency is similar but not exact because the wind turbines are facing non-uniform wake profiles due to incoming atmospheric boundary layer.

Figure 8 presents the axial direction wind speed profiles along vertical direction at various axial positions in the center plane for case $3(\mathrm{~L} 2=5 \mathrm{D})$. The reference position, $0 \mathrm{D}$ is the location of wind turbine WT1. The position of $-2.5 \mathrm{D}$ is away ahead from wind turbine WT1 and the position of 2.5D is the center between wind turbines WT1 and WT2. The position of 7.5D is the center between wind turbines WT2 and WT3, and the position of 12.5D is the rear position from wind turbine WT3 by 2.5D. The wind speed profile changes with the positions due to the wind speed deficit and power extraction by the rotor [6]. At the position of 12.5D, the wind speed recovers, as expressed in Figure 7.

The maximum velocity deficit is occurred at the reference height which is the center of rotor. After the last wind turbine, wake profile is recovered to the atmospheric boundary layer, however, the profile is not symmetric with respect to wake centerline because of shear layer and the tilting of the rotor. It should be noted that the velocity profile assumed to be a uniform profile mostly adopted for a wind farm design is invalid [4].

Figure 8. Axial direction wind speed profiles along vertical direction at various axial positions in the center plane for the case $3(\mathrm{~L} 2=5 \mathrm{D})$.

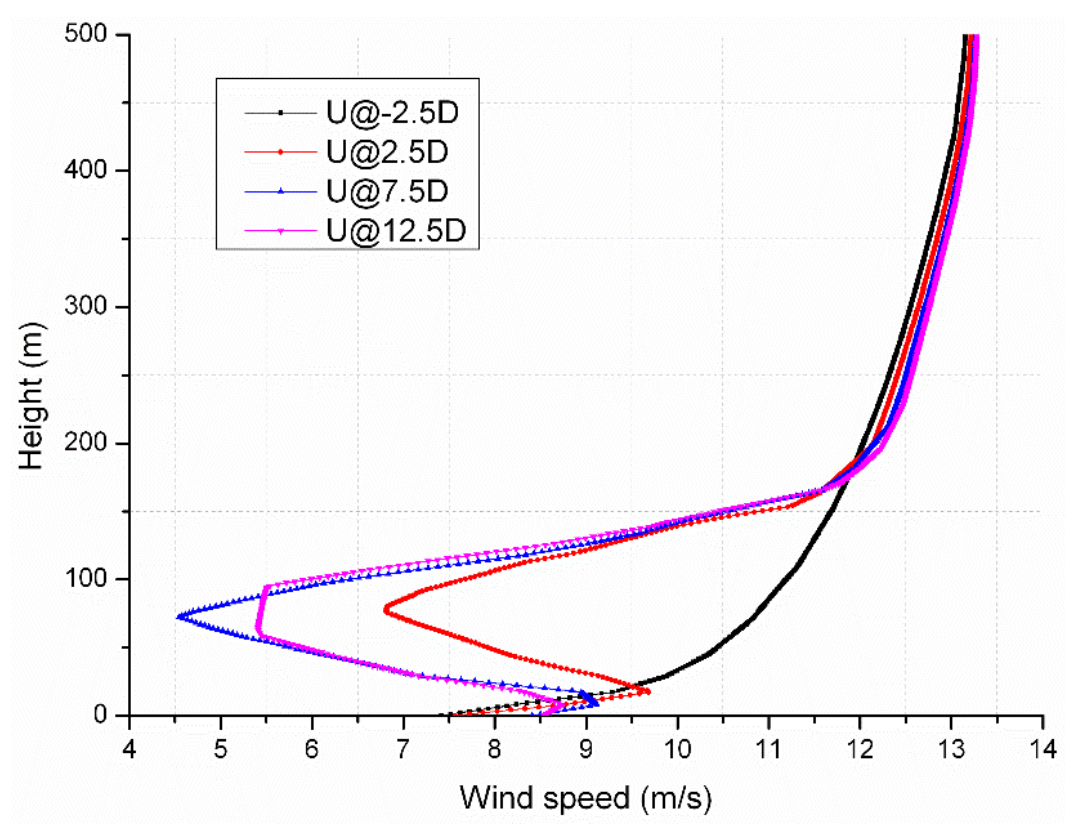

Figure 9 shows gage pressure profile along the centerline in streamwise direction at the reference height for case $3(\mathrm{~L} 2=5 \mathrm{D})$. A high pressure drop occurs across wind turbine rotors. The magnitude of the pressure drop decreases through wind turbines WT2 and WT3. The amount of energy extraction is proportional to the pressure drop, which explains why the aerodynamic power output of wind turbine WT3 is the smallest. The maximum pressure in front of turbine rotors WT1, WT2, and WT3 is decreasing from $24 \mathrm{~Pa}, 12 \mathrm{~Pa}$, and $7 \mathrm{~Pa}$, respectively, while the minimum pressure remains constant, $-12.5 \mathrm{~Pa}$. It can be explained that the maximum pressure depends on the square of incoming velocity, while the minimum pressure occurs at the dead water zone of wake flows. The maximum pressure ratio based on the peak pressure in front of WT1 for WT2 and WT3 are 0.50 and 0.29 , which are quite close to the corresponding power ratio, 0.41 and 0.29 . 
The pressure behind the rotor of wind turbine WT3 recovers to the atmospheric pressure in downstream direction due to the weakened wake [18]. During wind turbine operation, it is important to minimize exposing the wind turbine to turbulence. In real situation, strong tip vortices are formed at the blade tips then moves to downstream with spiral trajectory. In this study, only steady simulation was carried out. Unsteady simulation is needed for future research to understand the evolution of tip vortices and its interaction with downstream wind turbines.

Figure 9. Gage pressure distribution along the center line in streamwise direction at the reference height for case $3(\mathrm{~L} 2=5 \mathrm{D})$.

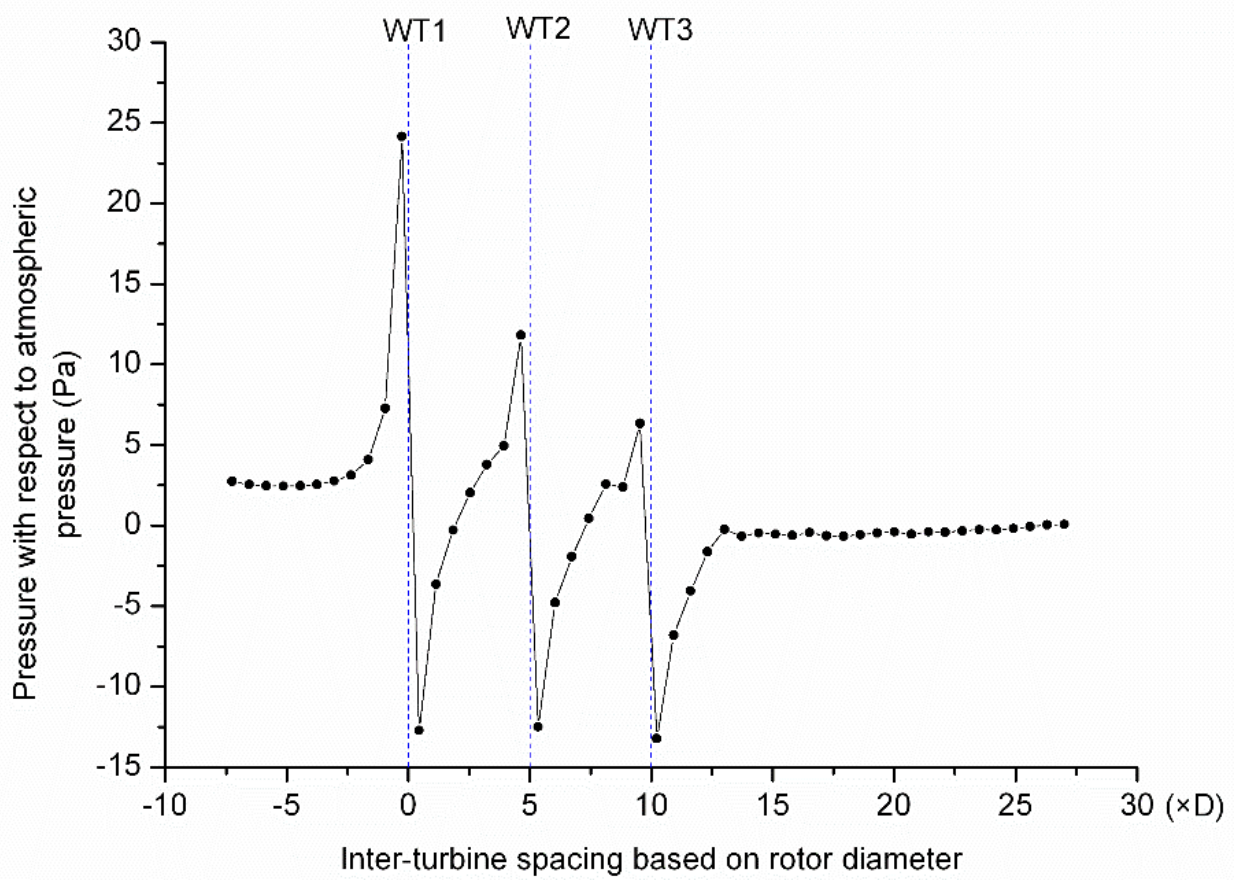

Figure $10 \mathrm{a}-\mathrm{c}$ show the pressure coefficient distributions on the pressure side and suction side of turbine blade at $\mu=0.8$ for WT1, WT2, and WT3, respectively. Here, $\mu=r / R$ is a non-dimensional position of the radius of the rotor. The detail specifications of blade at $\mu=0.8$ of the designed $2 \mathrm{MW}$ wind turbine are $2221 \mathrm{~mm}$ of chord length, $2.77^{\circ}$ of twist angle and the airfoil series is NACA 63-418 [12]. The pressure coefficient of the wind turbine WT1 blade was relatively unaffected by an increase in inter-turbine spacing. This is because of the undisturbed incoming free stream wind speed, which is relatively constant. On the other hand, as the inter-turbine spacing is decreased, the pressure coefficient of the wind turbine WT2 blade and the wind turbine WT3 blade departed more from the pressure coefficient of the wind turbine WT1 blade. The differences in the pressure side are more pronounced compared to those in the suction side. In addition, the differences at the leading edge section are more obvious compared to those in the trailing edge section. The amount of the difference in the pressure coefficient between the pressure side and the suction side is proportional to the aerodynamic power output. Therefore, the aerodynamic power output of wind turbines WT2 and WT3 can be increased when the inter-turbine distance is increased.

Regarding to the criterion to select an adequate inter-turbine distance in an offshore wind farm, L2 $=5 \mathrm{D}$ is a possible candidate based on the slope of power increases in WT2 and WT3 as shown in Figure 5 . 
Figure 10. Pressure coefficient distributions at $\mu=0.8$ on the wind turbine blade (NACA 63-418). (a) L2 = 3D; (b) L2 = 5D; (c) L2 = 7D.

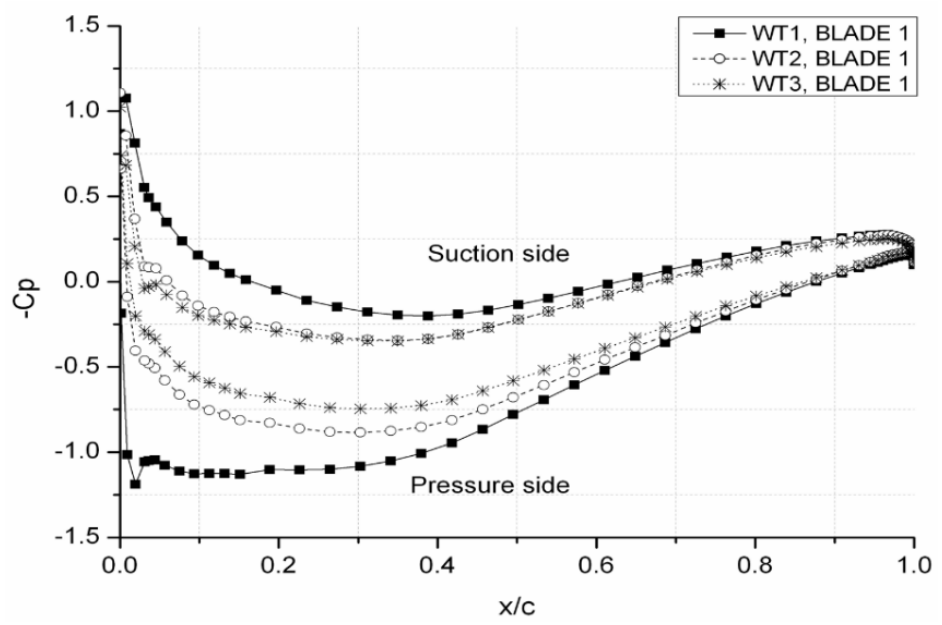

(a)

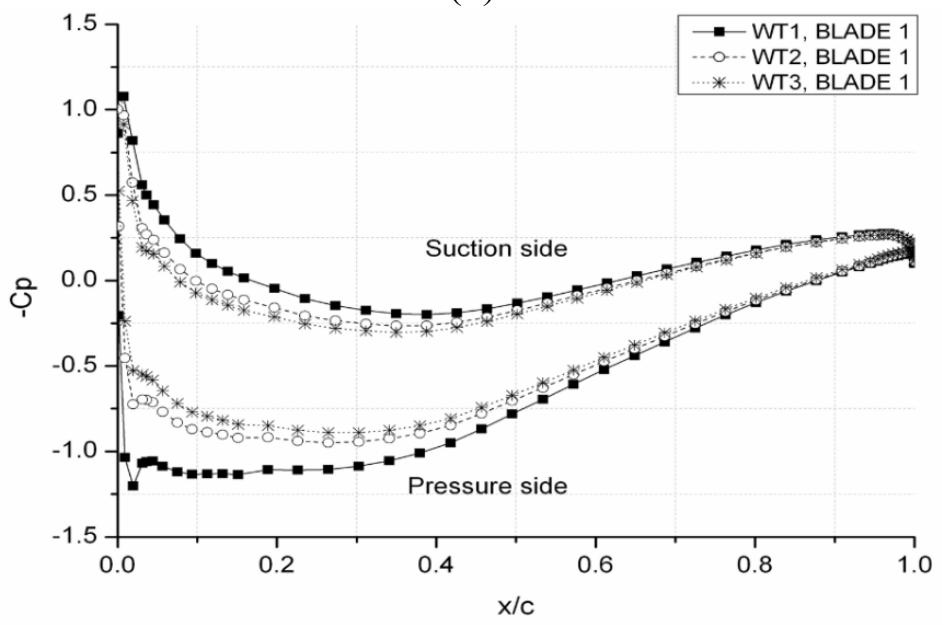

(b)

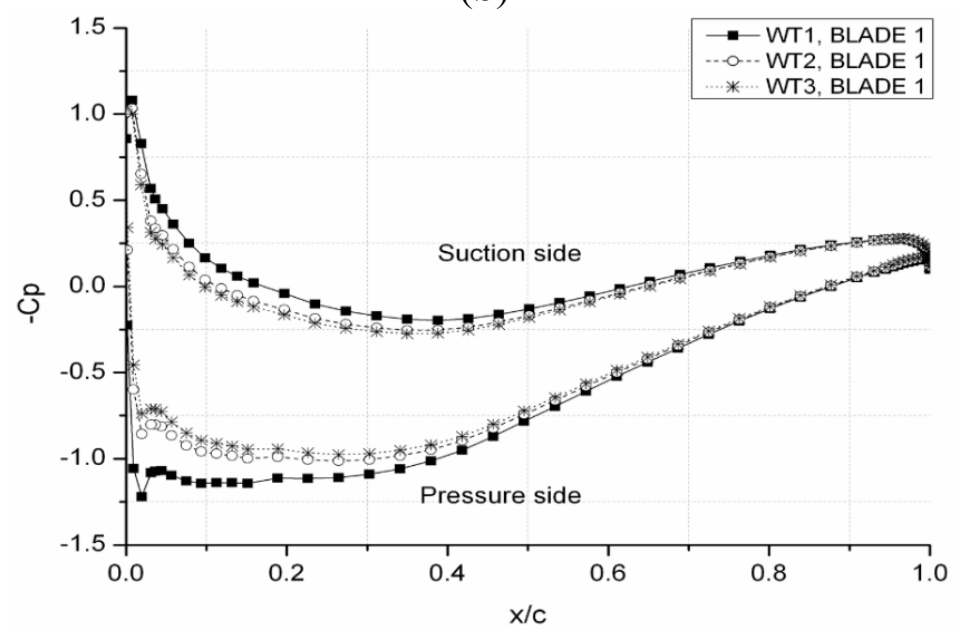

(c)

The hypothesis can be confirmed by comparison of the pressure coefficient distributions with respect to the inter-turbine distance. The distribution of pressure coefficients in case 1 (L2 = 3D) is quite different with that of case $3(\mathrm{~L} 2=5 \mathrm{D})$. However, the difference is relatively small between case $3(\mathrm{~L} 2=5 \mathrm{D})$ and case $5(\mathrm{~L} 2=7 \mathrm{D})$. 


\section{Conclusions}

A CFD study of the power output of a tandem arrangement of three sets of 2 MW class wind turbines as an offshore wind farm was performed using a full 3-D wind turbine model with an incoming atmospheric boundary layer. The effect of inter-turbine distance between three turbines was found to be crucial for the conceptual design of a wind farm layout. Surprisingly, the power outputs of the downstream wind turbines, WT2 and WT3 were decreased from $15 \%$ and $3.6 \%$ to $56 \%$ and $44 \%$ compared to that of the upstream wind turbine, WT1, as the inter-turbine distance was changed from 3D to 7D. There was a nonlinear relationship between the power ratio and the inter-turbine distance. As the inter-turbine distance increased, the power output of the downstream wind turbines increased because the wake effect became weaker. Beyond the inter-turbine distance of $5 \mathrm{D}$, the rate of increase in power output of the downstream wind turbine decreased since the downstream wind turbine was placed outside the strong wake region of the upstream turbine. The distributions of pressure coefficients on wind turbine blades confirm the results. Hence, 5D can be a design criterion for the interturbine distance of an offshore wind farm for the compromise between the aerodynamic power output and inter-turbine spacing. The results of this study can be effectively applied to offshore wind farm layout design, site evaluation, and power output prediction. CFD analyses of the wind farm with staggered wind turbines, different rotor rotational phases, and elevation differences should be carried out in the future. These results will show the quantitative characteristics of the different wind farm layouts.

\section{Acknowledgments}

This study was supported financially by the National Research Foundation (NRF) of Korea through a grant funded by the Korean government (No. 2011-0030013), and by the Korea Institute of Energy Technology Evaluation and Planning (KETEP) (No. 20113030020010, No. 20134030200290) and INNOPOLIS Foundation of Korea Ministry of Science, ICT \& Future Planning (No. B2013DD0031).

\section{Author Contributions}

Nak Joon Choi prepared this manuscript and designed wind turbine rotor. Sang Hyun Nam performed the CFD analysis. Jong Hyun Jeong performed meshing operation. This work was carried out under the supervision of Kyung Chun Kim. All authors carried out data analysis, discussed the results and contributed to write the paper.

\section{Conflicts of Interest}

The authors declare no conflict of interest.

\section{References}

1. Tong, K.C. Technical and economic aspects of a floating offshore wind farm. J. Wind Eng. Ind. Aerodyn. 1998, 74-76, 399-410.

2. Manwell, J.F.; McGowan, J.G.; Rogers, A.L. Wind Energy Explained-Theory, Design and Application; John Wiley \& Sons (Canada) Ltd.: West Sussex, UK, 2002. 
3. Wang, Z.-X.; Jiang, C.; Ai, Q.; Wang, C. The key technology of offshore wind farm and its new development in China. Renew. Sustain. Energy Rev. 2009, 13, 216-222.

4. Kusiak, A.; Song, Z. Design of wind farm layout for maximum wind energy capture. Renew. Energy 2010, 35, 685-694.

5. Choi, N.J.; Nam, S.H.; Jeong, J.H.; Kim, K.C. Numerical study on the horizontal axis turbines arrangement in a wind farm: Effect of separation distance on the turbine aerodynamic power output. J. Wind Eng. Ind. Aerodyn. 2013, 117, 11-17.

6. Montavon, C.; Jones, I.; Staples, C.; Strachan, C.; Gutierrez, I. Practical issues in the use of CFD for modeling wind farms. In Proceedings of the European Wind Energy Conference, Marseille, France, 16-19 March 2009.

7. Frandsen, S.; Barthelmie, R.; Pryor, S.; Rathmann, O.; Larsen, S.; Højstrup, J.; Thøgersen, M. Analytical modeling of wind speed deficit in large offshore wind farms. In Proceedings of the European Wind Energy Conference, London, UK, 22-25 November 2004.

8. Emeis, S. Meteorological Explanation of Wake Clouds at Horns Rev Wind Farm. Available online: http://www.dewi.de/dewi/fileadmin/pdf/publications/Magazin_37/07.pdf (accessed on 20 August 2010).

9. Brown, C. Offshore Wind Farm Helicopter Search and Rescue Trials Undertaken at the North Hoyle Wind Farm. Contract MSA 10/6/239. Maritime and Costguard Agency, UK, 2005. Available online: http: //www.dft.gov.uk/mca/helicopter_wind_farm_sar_trials-3.pdf (accessed on 20 May 2005).

10. Da Rosa, A.V. Fundamental of Renewable Energy Process; Acamedic Press: Waltham, MA, USA, 2009.

11. Kishinami, K.; Taniguchib, H.; Suzukia, J.; Ibanoc, H.; Kazunoud, T.; Turuham, M. Theoretical and experimental study on the aerodynamic characteristics of a horizontal axis wind turbine. Energy 2005, 30, 2089-2100.

12. Choi, N.J.; Kim, J.S.; Lee, S.M. Development and application of XD-BLADE software for the horizontal axis wind turbine blade design. In Proceedings of the KWEA Spring Conference, Kunsan National University, Gunsan, Korea, 27-29 May 2010, pp. 261-266.

13. Ray, M.L.; Rogers, A.L.; McGowan, J.G. Analysis of wind shear models and trends in different terrains. In Proceedings of the AWEA Windpower 2006 Conference, Pittsburgh, PA, USA, 4-7 June 2006.

14. DNV/Ris $\varphi$. Guidelines for Design of Wind Turbines; Jydsk Centraltrykkeri: Copenhagen, Denmark, 2002.

15. Laursen, J.; Enevoldsen, P.; Hjort, S. 3D CFD rotor computations of a multi-megawatt HAWT rotor. In Proceedings of the European Wind Energy Conference, Milan, Italy, 6-10 May 2007.

16. Frandsen, S.T.; Jørgensen, H.E.; Barthelmie, R.; Rathmann, O.; Badger, J.; Hansen, K.; Ott, S.; Rethore, P.-E.; Larsen, S.E.; Jensen, L.E. The making of a second-generation wind farm efficiency model complex. Wind Energy 2009, 12, 445-458.

17. Hansen, M.O.L.; Sørensena, J.N.; Voutsinasb, S.; Sørensenc, N.; Madsenc, H.Aa. State of the art in wind turbine aerodynamics and aeroelasticity. Prog. Aerosp. Sci. 2006, 42, 285-330.

18. Gonzales, J.S.; Gonzalez Rodriguezb, A.G.; Morac, J.C.; Santosa, J.R.; Payan, M.B. Optimization of wind farm turbines layout using evolutive algorithm. Renew. Energy 2010, 35, 1671-1681.

(C) 2014 by the authors; licensee MDPI, Basel, Switzerland. This article is an open access article distributed under the terms and conditions of the Creative Commons Attribution license (http://creativecommons.org/licenses/by/4.0/). 